sulfasalazine. Sixty-nine patients were achieved an excellent pain control outcome with these agents (Group A). Sixty-four patients who complained of intractable low back pain were switched to anti-TNF- $\alpha$ treatment (Group B). Twelve radiographic parameters were measured. Clinical outcome was assessed with the Bath AS Disease Activity Index (BASDAI), erythrocyte sedimentation rate (ESR), and C-reactive protein (CRP). All parameters were measured at enrolment, upon changing treatment agents, and every 6 months during follow-up. Results: Mean ESR, CRP, BASDAI, and thoracic kyphosis at baseline were significantly higher in group B. After treatment, group B had significantly higher lumbar lordosis and significantly better clinical outcomes. Correlation analysis revealed significant relationships between radiologic parameters and BASDAI On multiple regression analysis, lumbar lordosis was a significant predictor of BASDAI.

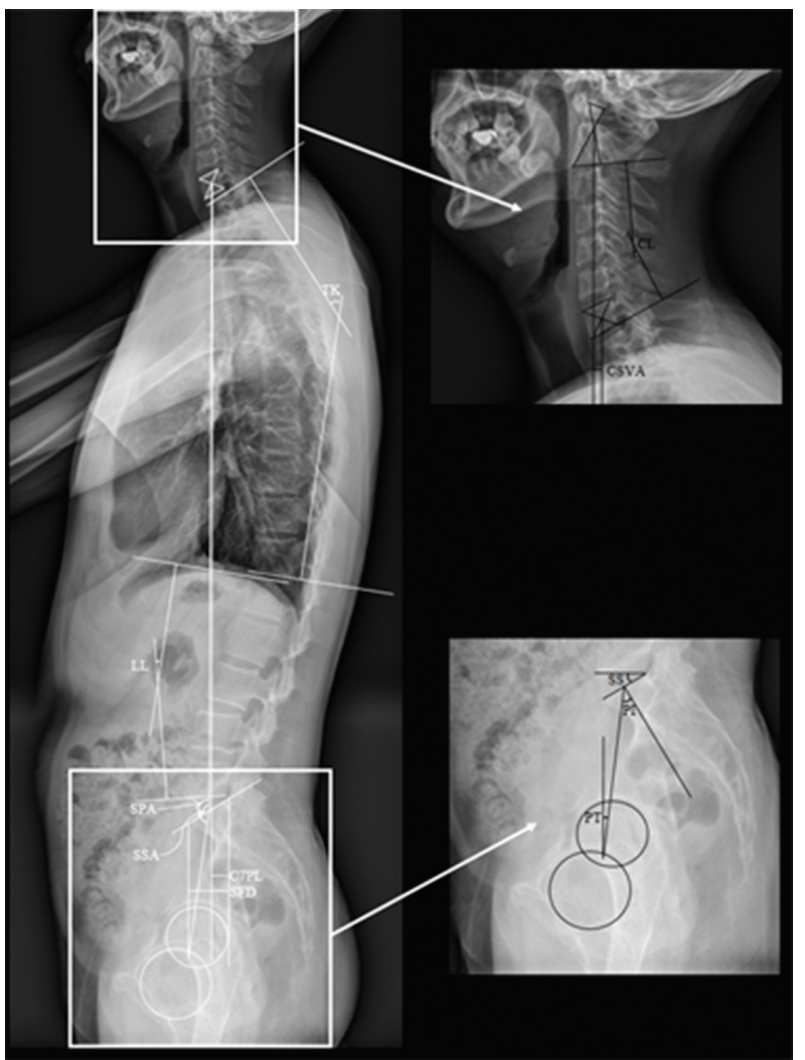

Abstract AB0839 - Figure

Conclusions: This study demonstrated a clear association between treatment agents and radiologic parameters in AS. Anti-TNF- $\alpha$ treatment improved lumbar lordosis and slowed thoracic kyphotic progression with improvement of clinical outcomes. Lumbar lordosis was a significant predictor of clinical outcome in AS patients treated with anti-TNF- $\alpha$

Disclosure of Interest: None declared

DOI: 10.1136/annrheumdis-2018-eular.3590

\section{AB0840 DETERMINATION OF SERUM LEVELS OF AND ANTI- DRUG ANTIBODY PRODUCTION AGAINST TNF INHIBITORS IN ANKYLOSING SPONDYLITIS: TESTING MAY BE USEFUL FOR THE ASSESSMENT OF COMPLIANCE BUT NOT THAT OF TREATMENT EFFECTIVENESS}

K. Gulyás, A. Medelle, N. Bodnár, Z. Szekanecz, S. Szántó. Department of Rheumatology, University of Debrecen, Faculty of Medicine, Debrecen, Hungary

Background: Targeted therapies, such as TNF-alpha inhibitors revolutionised the treatment of spondyloarthritides including ankylosing spondylitis (AS).
Objectives: To determine the correlation between serum TNF-alpha inhibitor levels of patients receiving biological therapy and concentration of anti-drug antibodies, disease activity (treatment effectiveness), age of patients and elapsed time since the onset of the diagnosis and from the initiation of the therapy.

Methods: Serum levels of TNF-alpha inhibitors $(\mathrm{mg} / \mathrm{ml})$ and concentration of antidrug antibodies $(\mathrm{AU} / \mathrm{ml})$ were measured in $37 \mathrm{AS}$ patients. Altogether 12 patients were treated with infliximab (IFX), 15 received adalimumab (ADA) and 10 received etanercept (ETN). Demographic data and parameters measuring disease activity (BASDAI) were also included in the analysis.

Results: A strong negative correlation was found between the concentration of anti-drug antibodies and drug serum levels (IFX: $R^{2}=0.833 ; A D A: R^{2}=0.426$; $E T N$ : $\mathrm{R}^{2}=0.587$ ). On the other hand, similar correlation could not be demonstrated between serum concentrations of IFX, ADA or ETN and other factors, such as age of the patient (IFX: $R^{2}=0.050$; $A D A: R^{2}=0.090$; ETN: $R^{2}=0.016$ ), BASDAI (IFX: $R^{2}=0.099 ; A D A: R^{2}=0.071 ; E T N: R^{2}=0.015$ ), disease duration (IFX: $R^{2}=0.024$ ADA: $R^{2}<0.001$; ETN: $R^{2}=0.182$ ) and time since the initiation of therapy (IFX: $R^{2}=0.008 ; A D A: R^{2}=0.052 ;$ ETN: $R^{2}=0.062$ ).

Conclusions: As anti-TNF-alpha antibodies decrease the serum concentration of TNF inhibitors. In our study, drug serum levels and anti-drug antibody concentrations significantly correlated with each other. However, similarly to some other reports, drug levels did not correlate with treatment efficacy. Therefore, routine assessment of serum drug and anti-drug antibody levels should not be recommended in the everyday practice in order to determine treatment effectiveness. However, the parallel evaluation of drug and anti-drug antibody levels may be effectively used in order to determine patient compliance in the case of subcutaneously administered drugs.

Disclosure of Interest: None declared

DOI: 10.1136/annrheumdis-2018-eular.4446

\section{AB0841 ASSESSMENT OF RELATIONSHIP BETWEEN LONELINESS, PERCEIVED SOCIAL SUPPORT, DEPRESSION AND MEDICATION ADHERENCE IN ANKYLOSING SPONDYLITIS PATIENTS}

E. Öksüz ${ }^{1}$, F.I. Cinar ${ }^{1}$, M. Cinar ${ }^{2}$, E. Tekgoz ${ }^{2}$, S. Yilmaz ${ }^{2} .{ }^{1}$ University of Health Sciences, Gulhane Faculty of Nursing; ${ }^{2}$ University of Health Sciences, Gulhane Faculty of Medicine, Department of Internal Medicine, Division of Rheumatology, Ankara, Turkey

Background: Ankylosing spondylitis (AS) is a chronic, progressive, inflammatory disease which can cause labour loss and deformities and requiring long-term treatment. Loneliness, perceived social support, depression, patients' beliefs about medicines and treatment may affect their medication adherence and treatment success.

Objectives: In this study, we aimed to investigate the relationship between loneliness, perceived social support, depression and medication adherence in AS patients.

Methods: This cross-sectional study was conducted in a tertiary rheumatology outpatient clinic. One hundred and nineteen AS patients were enrolled to the study. The socio-demographic and clinical features of the patients agreeing to participate were recorded to the "Patient Assessment Form". The patients" disease activity and functional status were determined with the Bath Ankylosing Spondylitis Disease Activity Index (BASDAI, and the Bath Ankylosing Spondylitis Functional Index (BASFI), respectively. The pain and global assessment of the patients' were assessed with a numerical visual analogue scale (nVAS; 0 $10 \mathrm{~cm}$ ). The medication adherence of the patients was assessed with the Morisky Green Levine Scale (MGLS). The UCLA Loneliness Scale, the Multidimensional Scale of Perceived Social Support (MSPSS) and the Beck Depression Inventory (BDI) were used to determine loneliness, perceived social support, and depression of the patients.

Results: One hundred five patients $(88.2 \%)$ were male, the mean age was 35.80 \pm 9.08 years, and the mean disease duration was $9.88 \pm 6.34$ years. The mean BASDAI, BASFI and patient global assessment scores were; $4.57 \pm 2.63,3.23$ \pm 2.76 , and $4.13 \pm 3.23$, respectively. According to the MGLS medication adherence groups, patients with low medication adherence had higher BASDAI, spinal pain, spinal pain at night, fatigue and patient global assessment scores and had lower mean ages $(p<0.05)$. Among the MGLS medication adherence groups, patients with low medication adherence had lower MSPSS scores, and had higher UCLA Loneliness Scale and Beck Depression Inventory scores $(p=0.037$, $\mathrm{p}<0.001, \mathrm{p}=0.022$, respectively) (table 1 ). 
Abstract AB0841 - Table 1. Comparison of the perceived social support, depression and loneliness scores with the Morisky Green Levine Scale subgroups.

\begin{tabular}{|c|c|c|c|c|c|c|}
\hline \multirow[b]{2}{*}{ Characteristics } & \multicolumn{6}{|c|}{$\begin{array}{l}\text { Morisky Green Levine } \\
\text { medication adherence } \\
\text { groups }\end{array}$} \\
\hline & Overall & $\begin{array}{c}\text { High } \\
(n=43)^{a}\end{array}$ & $\begin{array}{l}\text { Medium } \\
(n=66)^{b}\end{array}$ & $\begin{array}{c}\text { Low } \\
(n=10)^{c}\end{array}$ & $\mathbf{F}$ & $p$ \\
\hline $\begin{array}{l}\text { Multidimensional Scale of } \\
\text { Perceived Social Support total } \\
\text { score }^{12-84 *}\end{array}$ & $\begin{array}{r}63.52 \\
\pm 17.13\end{array}$ & $\begin{array}{r}65.09 \\
\pm 16.85\end{array}$ & $\begin{array}{c}64.65 \\
\pm 16.59\end{array}$ & $\begin{array}{r}49.30 \\
\pm 17.01\end{array}$ & 3.958 & 0.022 \\
\hline $\begin{array}{l}\text { Beck Depression Inventory }(0- \\
63)^{*}\end{array}$ & $\begin{array}{r}13.65 \\
\pm 10.41\end{array}$ & $\begin{array}{r}13.07 \\
\pm 11.29\end{array}$ & $\begin{array}{l}12.15 \\
\pm 8.51\end{array}$ & $\begin{array}{r}26.10 \\
\pm 10.73\end{array}$ & 8.952 & $<0.001$ \\
\hline UCLA Loneliness Scale $20-80$ * & $\begin{array}{c}37.34 \\
\pm 11.22\end{array}$ & $\begin{array}{r}35.19 \\
\pm 11.26\end{array}$ & $\begin{array}{c}37.56 \\
\pm 10.90\end{array}$ & $\begin{array}{r}45.20 \\
\pm 10.56\end{array}$ & 3.388 & 0.037 \\
\hline
\end{tabular}

F: Oneway ANOVA, Statistically significant between a and $c$, and b and $c(p<0.05)$. ${ }^{*}$ It shows the lowest-highest scores that can be taken from the scale and its sub-dimensions.

Conclusions: In this study, it was shown that as the average age and social support scores of patients decreased, and as the BASDAI, spinal pain, spinal pain at night, fatigue, patient global assessment, loneliness and depression scores increased, adherence to treatment were decreased. It is thought that patients should be handled holistically in terms of biopsychosocial aspect in order to improve adherence to medical treatment.

Disclosure of Interest: None declared

DOI: 10.1136/annrheumdis-2018-eular.5873

\section{AB0842 DRUG SURVIVAL AND EFFECTIVENESS OF THE FIRST TNF INHIBITORS IN PATIENT WITH LATE ONSET SPONDYLARTHRITIS: TREASURE REAL-LIFE RESULTS}

N. Alpay Kanıtez ${ }^{1}$, S. Kiraz ${ }^{2}$, I. Ertenli² ${ }^{2}$ O. Küçükşahin ${ }^{2}$, E. Dalkılıç ${ }^{3}$, C. Bes ${ }^{1}$, T. Kaşifoğlü ${ }^{4}$, H. Emmungil ${ }^{5}$, S.S. Koca ${ }^{6}$, M. Çınar ${ }^{2}$, S. Yılmaz ${ }^{2}$, V. Yazısız ${ }^{7}$,

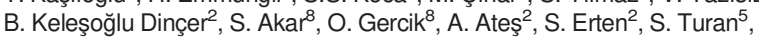
B. Yağız ${ }^{3}$, B. Öz ${ }^{6}$, S. Yaşar Bilge ${ }^{4}$, L. Kılıç ${ }^{2}$, G.K. Yardımcı ${ }^{2}$, B.N. Coşkun ${ }^{3}$ U. Kalyoncu ${ }^{2} .{ }^{1}$ TReasure biological registry, Istanbul; ${ }^{2}$ TReasure biological registry, Ankara; ${ }^{3}$ TReasure biological registry, Bursa; ${ }^{4}$ TReasure biological registry, Eskişehir, ${ }^{5}$ TReasure biological registry, Edirne; ${ }^{6}$ TReasure biological registry, Elazığ; ${ }^{7}$ TReasure biological registry, Antalya; ${ }^{8}$ TReasure biological registry, Izmir, Turkey

Background: Spondylartritis $(\mathrm{SpA})$ are usually observed in young patients and a clinical onset after 45 years is rare. The average life expectancy is getting longer and the proportion of late onset of SpA in rheumatology practice may became more common. SpA patients with late onset may have a distinctive clinical pattern in terms of functional impairment, extra-articular disease, co-morbidities and treatment status.

Objectives: The aim of this study was to compare the drug survival and effectiveness of tumour necrosis factor (TNF) inhibitors in patients with late onset SpA (LoSpA) compared with early onset SpA (EoSpA).

Methods: TReasure is a prospective, multicenter biological treatments registry from Turkey since 2016. It includes 15 different rheumatology centres. Patients with SpA fulfilling the ASAS criteria from TReasure database were divided into two groups as LoSpA (symptom onset $>45$ years of age) and EoSpA (symptom onset $\leq 45$ years of age). Drug retention rates of first TNF inhibitors were calculated using the time until drug discontinuation independent of the reason that drug interruption. Specific reasons for discontinuing drugs were also assessed.

Results: Of $1382 \mathrm{SpA}$ patients treated with TNF inhibitors, 9.4\% $(n=130)$ were included in the LoSpA and $90.6 \%(n=1252)$ were included in the EoSpA group. LoSpA had more female, enthesitis and psoriasis The median treatment duration was 53 months in LoSpA and 61 months in EoSpA. The baseline disease activity measures were similar except from ASDAS-ESH which is higher in LoSpA (table 1). The rate of major treatment response (BASDAI50) was lower in LoSpA than EoSPA at the last visit ( $26.1 \%$ vs $46.2 \%$; $p=0.009$ ). Regarding the survival rates of TNF inhibitors, there was no significant difference between the patient groups (figure 1). The major cause of discontinuation in both of groups was drug ineffectiveness $(68.6 \%$ in LoSpa and $60 \%$ in EoSpA, p>0.05).

Abstract AB0842 - Table 1

\begin{tabular}{lccc}
\hline & LoSpA n: 130 & EoSpA n:1252 & p values \\
\hline Age [median (min-max)] & $56,5(45-75)$ & $35(0-76)$ & $<0.001^{*}$ \\
Female n (\%) & $90(69)$ & $494(40)$ & $<0.001^{*}$ \\
Disease duration [median (min-max)] & $61(1-334)$ & $108(0-686)$ & $<0.001^{*}$ \\
BASDAI [median (min-max)] & $6.1(0-10)$ & $6(0-10)$ & 0.748 \\
BASFI [median (min-max)] & $5.3(0-10)$ & $4.5(0-10)$ & 0.098 \\
ASDAS-ESH [median (min-max)] & $3.29(1.23-4.92)$ & $2.91(0-5.7)$ & $0.001^{*}$ \\
ASDAS-CRP [median (min-max)] & $3.55(1.49-5.92)$ & $3.35(0.7-8)$ & 0.251 \\
\hline
\end{tabular}

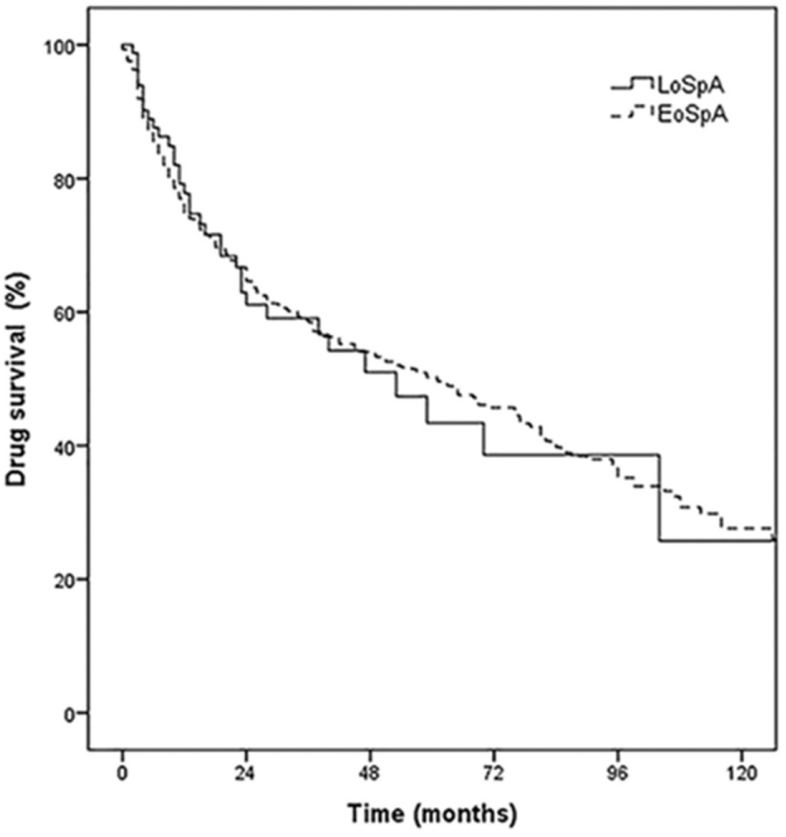

Abstract AB0842 - Figure 1

Conclusions: LoSpA patients were almost $10 \%$ of all biological registry. LoSpA patients were predominantly female, and they had relatively higher baseline disease activity and lower biological treatment response. On the other hand the drug survival rate and discontinuation reasons of TNF inhibitors in the LoSpA group was comparable to that in the younger group.

\section{REFERENCE:}

[1] - Chen HA, Chen CH, Liao HT, Lin YJ, Chen PC, Chen WS, et al. Clinical, functional, and radiographic differences among juvenile-onset, adult-onset, and late-onset ankylosing spondylitis. J Rheumatol. 2012; 39:1013-8

Disclosure of Interest: None declared

DOI: 10.1136/annrheumdis-2018-eular.4844

\section{AB0843 EFFECT OF TNF INHIBITORS ON BONE MICROARCHITECTURE IN PATIENTS WITH ANKYLOSING SPONDYLITIS: A LONGITUDINAL STUDY BASED ON HIGH-RESOLUTION PERIPHERAL QUANTITATIVE BASED (HRPQCT)}

N. Nigil Haroon ${ }^{1}$, E. Szabo ${ }^{2}$, A.M. CHEUNG ${ }^{3}$, R. Inman ${ }^{4} .{ }^{1}$ Medicine, Northern Ontario School of Medicine, Sudbury; ${ }^{2}$ Osteoporosis program, UHN; ${ }^{3}$ Medicine, Univ of Toronto; ${ }^{4}$ Medicine, unit of Toronto, Toronto, Canada

Background: Ankylosing spondylitis (AS) is associated with high risk of fractures. BMD, bone microarchitecture and strength are negatively affected in AS. TNF inhibitors such as etanercept, adalimumab, golimumab and infliximab are the mainstay of treatment in AS. However no data is available on the effect of TNF inhibitors on bone microarchitecture and strength.

Objectives: This study aimed to assess the effect of TNF inhibitors on bone microarchitecture in patients with AS.

Methods: AS was defined by Modified New York criteria. Areal BMD was meas ured by DXA. Volumetric BMD (vBMD) and bone microarchitecture were measured using highresolution peripheral quantitative $C T$ (HRPQCT) at the radius and tibia at baseline and after one year of treatment with TNF inhibitors. Intake of calcium and vitamin D were optimised.

Results: There were 31 subjects ( $58 \%$ men). Mean (+SD) age and BASDAI were $40+14$ years and $4.1+2.1$ respectively. Median duration of disease was 14 (IQ: 6.5-25.5) years. Mean duration of follow-up was 15 months. Areal BMD $(n=22)$ at lumbar spine $(1.053+0.235$ vs. $1.049+0.202, p=0.89)$, total hip $(0.944+0.152$ vs $0.912+0.164, p=0.5)$, and femoral neck $(0.955+0.151$ vs. $0.954+0.191, p=0.2)$ did not change significantly. HRpQCT $(n=31)$ on follow-up demonstrated that total, trabecular and cortical volumetric BMD were unchanged at both radius and tibia (table 1). Also, HRpQCT based trabecular parameters such as trabecular number, thickness and separation, BV/TV and cortical parameters such as cortical porosity and thickness remained stable (table 1). FEA estimates of bone stiffness and 